\title{
Téoros
}

Revue de recherche en tourisme

\section{La pêche blanche à Ville de la Baie et dans le Bas-Saguenay}

\section{Langis Bouchard}

Volume 8, numéro 3, novembre 1989

Tourisme hivernal

URI : https://id.erudit.org/iderudit/1080312ar

DOI : https://doi.org/10.7202/1080312ar

Aller au sommaire du numéro

Éditeur(s)

Université du Québec à Montréal

ISSN

0712-8657 (imprimé)

1923-2705 (numérique)

Découvrir la revue

Citer cet article

Bouchard, L. (1989). La pêche blanche à Ville de la Baie et dans le Bas-Saguenay. Téoros, 8(3), 34-34. https://doi.org/10.7202/1080312ar d'utilisation que vous pouvez consulter en ligne.

https://apropos.erudit.org/fr/usagers/politique-dutilisation/ 


\section{La pêche blanche à Ville de la Baie et

Dans le domaine touristique, on est tou-

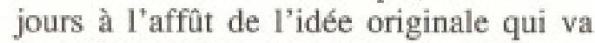
contribuer à faire connaitre un milieu ou une région. Onparle souvent de laspécificité du produit touristique, mais il y a loin de la coupe aux lèvres entre l'idée et la concrétisation. Le produit touristique de Ville de La Baie et du Bas-Saguenay est principalement constitué par la présence du magnifique fjord du Saguenay. Rappelons qu'un fjord est une rivière profondément encaissée, surcreusée par un glacier lors de l'époque glaciaire qui s'est terminée il y a environ 13000 ans. Les paysages sont a couper le souffle et naturellement, leurmise en valeur passe par la présence du Parc du Saguenay et par la miseen service de bateaux offrant des croisières. Encore une fois, nous rencontrons ici le problème majeur de notre industrie touristique qui s'échelonne sur une saison trop courte. On cherchait donc, comme plusieurs autres intervenants du domaine touristique, à étaler notre saison touristique sur une période beaucoup plus longue, tout en voulant miser sur l'élément majeur de notre produit, le fjord du Saguenay. Au plus fort de l'hiver 1983, on avait remarqué que 4 ou 5 pêcheurs se construisaient des cabanes qu'ils transportaient sur la glace de La Baie des Ha! Ha!, immense plan d'eau jouxtant Ville de La Baie, et passaient ainsi une bonne partie de l'hiver à pêcher. Ville de La Baie possếdait à cette époque un festival d'hiver comme plusieurs villes du Québec, ni mieux ni pire que celui des autres villes, sonenvergure bien locale lui promettait un avenir quelconque, tandis qu à quelques kilomètres de Ville de la Baie se déroulait le pompeux Carnaval de Chicoutimi. L'idée des planificateurs était bien sûr de faire de la pêche blanche l'activité principale du festival $\mathrm{d}^{\dagger}$ hiver. Profitant de quelques contacts et de l'existence des programmes fédéraux, nous avons obtenu une subvention pour la construction de 30 cabanes à pêche. Le projet aété offert à l'organisation du festival qui a accepté d'emblée, trouvant l'occasion belle d'avoir une activité originale. De-

Monsieur Langis Bouchard est directeur de l'Office du tourisme de Ville de La Baie et du Bas-Saguenay puis, le mouvement a fait boule de neige, à un point tel qu" Action Baieriveraine" (organisme responsable de la gestion de la péche blanche sur la Baie des Ha! Ha!) doit gérer des problèmes de croissance. Durant la saison hiver 88-89, 1321 cabanes à pêche ont été comptées sur le fjord du Saguenay. De ce nombre, 642 se sont localisées sur la Baie des $\mathrm{Ha}$ ! Ha!. Sur cette demière, on estime la fréquentation à environ 100000 personnes pour 83 jours d'activités. D'après les relevés d" Action Baieriveraine", on aurait prélevé de la Baie, durant l'hiver 88 89,2219 morues, 51558 cébastes, 6502 douzaines d'éperlans, 123 turbots et 191 anguilles. Malheureusement, nous n'avons pu obtenir les chiffres correspondants pour St-Fulgence, Sainte-Rose-du-Nord, Rivière-Éternité et l'Anse Saint-Jean.

Quant à l'impact économique de la pêche blanche, "Action Baieriveraine" et l'Office du tourisme estiment à un peu plus de 1.2 million les retombées de cette activité pour Ville de La Baie. La part la plus importante de ces retombées revient aux dépenses reliées aux cabanes privées, environ 650 $000 \$$. Bien entendu, les aubergistes vendent des forfaits pêche blanche; dans les seules municipalités de l'Anse Saint-Jean et de Rivière-Eternité, le taux d'occupation

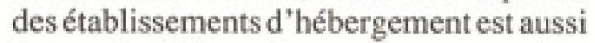
bon qu'en été; de plus en plus, on constate l'existence de deux saisons touristiques. Investir dans le Bas-Saguenay devient de plus en plus intéressant pour les gens d'affaires et c'était l'objectif visé par les planificateurs.

Une autre avenue de développement s'offrant au Bas-Saguenay: un important centre de ski alpin, localisé au MontÉdouard à $1^{*}$ Anse Saint-Jean, devrait apporter de l'eau au moulin. Le développement de la motoneige est également envisagé. Le produit touristique d'hiver en serait un des plus attractifs et diversifiés du Québec. Les petites municipalités rurales de ce milieu en ont grandement besoin, leur économie traditionnellement orientée vers l'exploitation forestière est en crise, due à la rupture de stock. Le développement touristique représente une solution pertinente à leur problème.

Bien entendu, comme nous l'avons déja énoncé, ce développement pose plusieurs problèmes. L'un de ces problèmes est causé par la pollution; actuellement, la pêche au crabe et à la crevette est interdite dans le fjord du Saguenay. On sait que la crevette s'y trouve en abondance et la venue de chalutiers, qui, par leur méthode de pêche, brassent les sédiments, libèrent ainsi les polluants emprisonnés dans les sédiments. Les pêcheurs de l'Anse Saint-Jean ont cependant développé une technique artisanale qui permet aux pếcheurs sportifs de capturer la crevette sans dommage causé à l'environnement. Le seul hic, le taux de contamination de la crevette qui tarde à baisser.

On constate un autre problème: celui de la gestion de la ressource faunique. Comment se comportent les especes, vivent-elles dans un bassin ouvert ou fermé par rapport au fleuve St-Laurent? Doit-on imposer des quotas? Il semble que l'achalandage, la circulation sur la glace, influencent le nombre de captures; doit-on établir des normes quant à la circulation des véhicules motorisés? On constate également qu'il y a deux types de pêcheurs; l'un davantage porté sur les contacts interpersonnels; cette clientèle correspondant souvent à la clientèle locale et l'autre davantage sportif et quí vient de l'extérieur de la région. L'un et l'autre ont des besoins spécifiques et les organisateurs doivent trouver des réponses différentes pour satisfaire leurs attentes.

En fait, la pêche blanche est un très beau produit touristique qui ajoute au caractère attractif du produit touristique hivemal du Québec. Il posecependant quelques problèmes environnementaux qui ne sont pas sans solutions. Mais force est de constater que cette activité devient de plus en plus populaire et constitue une activité économique qui mérite que des efforts sérieux soient consentis pour sa mise en valeur. $f$ 